\title{
Postural changes, dysphagia, and systemic sclerosis
}

Pilar Barrera, Alphons A den Broeder, Frank H J van den Hoogen, Baziel G M van Engelen, Leo B A van de Putte

\section{Case history}

In 1993, a 61 year old, previously healthy man, developed stiffness and skin thickening of the hands and upper limbs, Raynaud's phenomenon, and exertional dyspnea. Examination showed a diffuse systemic sclerosis (SSc), moderate hypertension (160/95 $\mathrm{mm} \mathrm{Hg}$ ), a reduced pulmonary diffusion capacity (TLC $107 \%$ predicted, DLCO $68 \%$ predicted), and asymptomatic oesophageal dysmotility. Treatment with D-penicillamine (D-Pen) $750 \mathrm{mg} /$ day and enalapril was started and, except for extension of the skin involvement to the trunk and lower limbs, the disease's course was uneventful for three years.

In August 1996 he was examined in another centre because of complaints of progressive fatigue, cervical anteflexion, proximal dysphagia, and weight loss. The patient denied having low back pain, and there were no symptoms suggesting arthritis, psoriasis, Reiter's syndrome or inflammatory bowel diseases.

Departments of Rheumatology P Barrera

A A den Broeder

F H J van den Hoogen

L B A van de Putte

and Neurology B G $M$ van Engelen

University Hospital, Nijmegen, the Netherlands

Correspondence to: Dr P Barrera, Department of Rheumatology, University Hospital Nijmegen, PO Box 9101, 6500 HB Nijmegen, the Netherlands.

Accepted for publication 2 April 1998

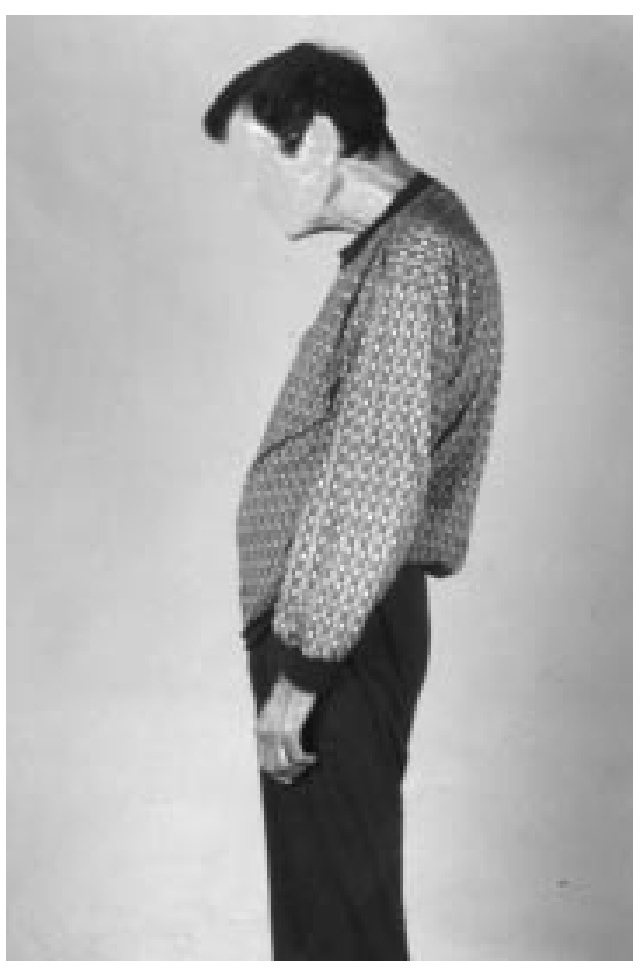

Figure 1 Posture of the patient at referral. Note the weakness of neck extensor muscles causing head drop.
Routine laboratory investigations showed an increased erythrocyte sedimentation rate (ESR) $(63 \mathrm{~mm} / 1 \mathrm{st} \mathrm{h})$, creatinine $(108 \mu \mathrm{M} / \mathrm{l}$; normal $60-100 \mu \mathrm{M} / \mathrm{l})$, aspartate aminotransferase (ASAT $53 \mathrm{u} / 1$; normal <25), and alanine aminotransferase (ALAT $38 \mathrm{u} / \mathrm{l}$; normal <25) and a slight proteinuria ( $0.44 \mathrm{~g} /$ day $)$.

The diagnosis ankylosing spondylitis was considered mainly because of his posture. HLA B27 typing was positive, however radiological examination showed only cervical arthrosis and periarticular calcifications in hands and feet. Radiographs and computed tomography of the pelvic joints showed no evidence of sacroiliitis. The anteflexion of the head was considered to be the result of dermal sclerosis and the slightly increased transaminases and proteinuria were attributed to D-Pen treatment and considered acceptable. Treatment with omeprazole was started and the dose of D-Pen increased to $1000 \mathrm{mg} /$ day.

In November 1996 he was referred to our centre for further investigation. He complained of a progressive "dropped head", which prevented him from being able to look straight ahead (fig 1). He had myalgias at the neck and shoulders, proximal dysphagia for solids and fluids, and choked regularly. He had noticed fatigue, a change in his voice to an open nasal speech and had lost $15 \mathrm{~kg}$ in eight months. At admission the dermal sclerosis affected his hands, forearms, feet, lower legs, face, neck, and trunk and there were no skin changes suggestive for dermatomyositis. The anteflexion of the cervical spine (70 degrees) could be corrected passively but not actively and resulted

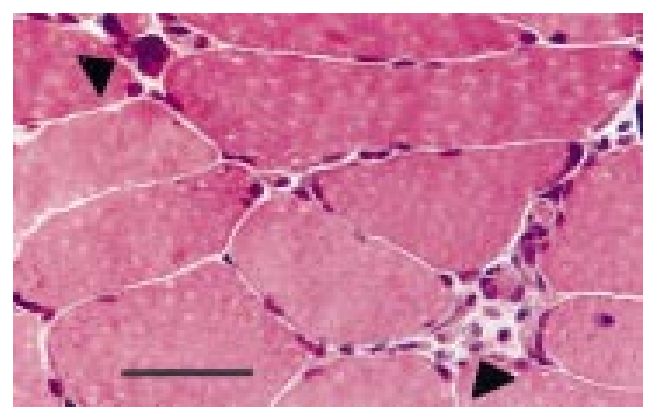

Figure 2 Histological section. Note the variation in fibre size, an atrophic fibre with pyknotic nuclei (upper left arrow), an atrophic fibre containing some myophages (bottom right arrow). (Haematoxylin and eosin; black bar: $50 \mu \mathrm{m})$ 


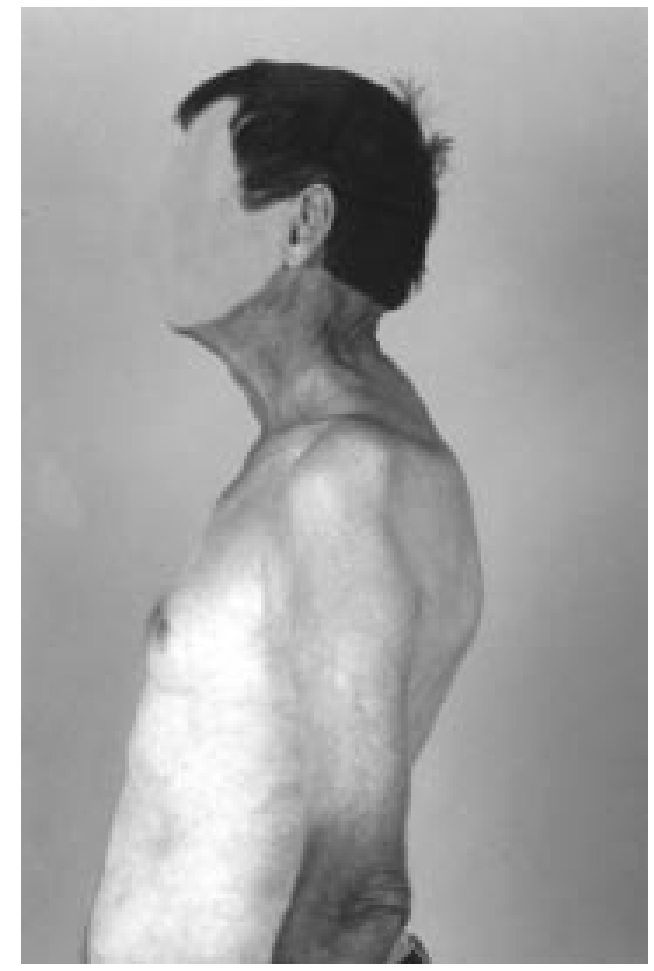

Figure 3 Posture of the patient after some weeks of treatment with corticosteroids and methotrexate.

in an occiput wall distance of $32 \mathrm{~cm}$. The respiratory excursion of the chest was limited by the sclerotic skin but the lumbar flexion index was normal and there was no pain on pressure on the sacroiliac joints. The "dropped head" and nasal speech were caused by a profound weakness of neck extensor (Medical Research Council (MRC) scale 2/5) and palatum muscles and there was also a symmetric weakness of proximal limb muscles (MRC scale 3-4/5). Myasthenic symptoms, such as involvement of ocular or facial muscles or worsening fatigue on repetitive contraction, were absent. Laboratory data showed a raised ESR $(63 \mathrm{~mm} / 1 \mathrm{st} \mathrm{h})$, increased serum enzymes (creatine kinase (CK) $1600 \mathrm{u} / 1$; normal <90), ASAT (74 u/l; normal <25), ALAT (43 u/l; normal <25), and LDH (899 u/l;
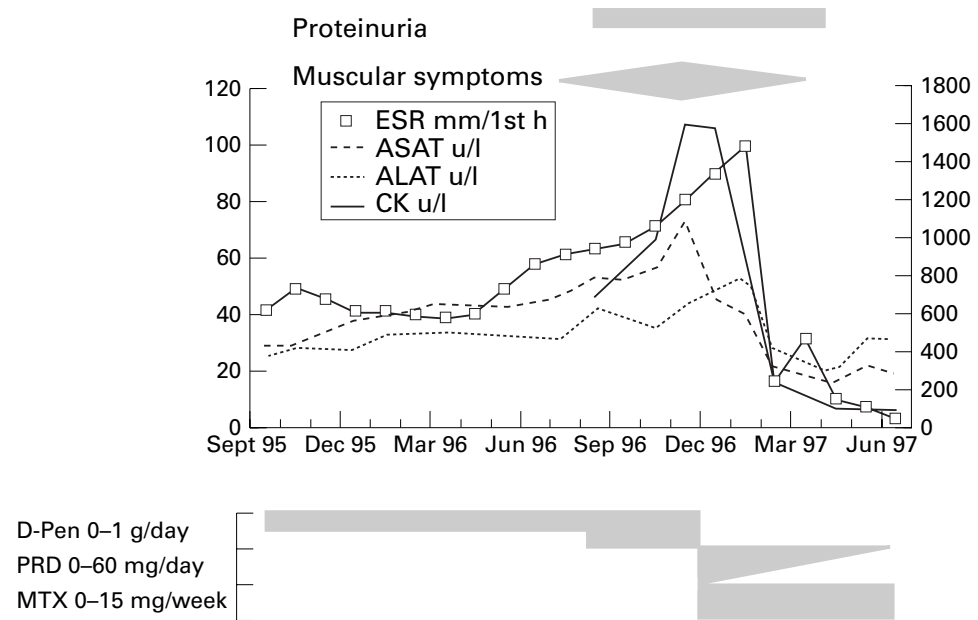

Figure 4 Clinical course, treatment, and enzyme abnormalities. On the left y axis erythrocyte sedimentation rate (ESR), aspartate aminotransferase (ASAT), alanine aminotransferase (ALAT). On the right y axis creatine kinase (CK), D-penicillamine (D-Pen), prednisone (PRD), methotrexate (MTX). normal <330) and a mild proteinuria (0.45 $\mathrm{g} /$ day). There was no evidence of cholestasis, serum electrolytes disturbances or monoclonal gammopathy. Antinuclear antibodies were positive (homogeneous and nucleolar pattern), and a non-specific band was observed on counterimmunoelectrophoresis but not on immunoblotting. No disease specific antibodies, including anti-dsDNA, anti-histone, anti-mitochondrial, anti-skeletal muscle, anti-acetyl choline receptor, and other myositis (anti-Jo1) or scleroderma specific (anti-topoisomerase I, anticentromere) antibodies, were observed. HLA typing showed A 30,31; B 13,27; Bw4; DR 3,7; DR52; DR53.

Electromyography (EMG) showed evidence of severe proximal myopathy with polyphasic potentials, small units, fibrillations, and denervation. A percutaneous biopsy specimen was obtained from the left quadriceps, which was clinically affected and showed contralateral myopathic changes on EMG. Myopathic changes consisting of fibre size variation, internalisation of nuclei, atrophic fibres with pyknotic nuclei, focal necrosis, and necrotic fibres filled with myophages were seen (fig 2). Inflammatory infiltrates were scarce and localised to the fascicles and neither trichinella or toxoplasma cysts nor basophilic vacuoles (characteristic for inclusion body myositis) or amyloid deposits were observed.

Electrocardiography and echocardiography disclosed no abnormality. Chest radiography showed no signs of basilar fibrosis and pulmonary function tests revealed no abnormality with exception of the pre-existing reduced diffusion capacity. Besides a moderate distal oesophageal hypomotility on recumbence, gastrointestinal series showed cricopharyngeus muscle spasm and contrast aspiration.

D-Pen was discontinued and treatment with oral prednisone (initial dose $60 \mathrm{mg} /$ day) and methotrexate im (15 mg/week) was started. Clinical improvement was rapid: the strength of neck extensors and proximal muscles recovered within 2-4 weeks (fig 3). The fatigue, myalgias, and proximal dysphagia gradually subsided while prednisone was tapered off. Proteinuria ceased and serum muscle enzymes returned to normal values within five months (fig 4).

\section{Discussion}

We present a patient with SSc developing new constitutional, muscular, and gastrointestinal symptoms three years after initial diagnosis. The slow onset of complaints and the fact that they could be partially attributed to the pre-existent connective tissue disease were misleading. Nevertheless, correct interpretation of the clinical history and the abnormalities on physical and laboratory examination could have lead to an earlier diagnosis. Some diagnostic problems arising from this case will be further discussed here.

Before referral, ankylosing spondylitis was considered. Was this likely to be present and which investigations should have been performed to find this out? Though both entities are not mutually exclusive, there is no known association between SSc 
Table 1 Toxicity of D-Penicillamine treatment

\begin{tabular}{|c|c|c|c|}
\hline & Relatively frequent & Rare & Very rare \\
\hline General & & Fever & Dizziness \\
\hline \multirow[t]{3}{*}{ Mucocutaneous } & Pruritus & Pemphigus & Elastosis perforans serpiginosa \\
\hline & Rash/dermatitis & Alopecia & Increased risk penicillin allergy? \\
\hline & Oral ulcers and stomatitis & & \\
\hline \multirow[t]{2}{*}{ Gastrointestinal } & Altered taste & Anorexia, diarrhoea & Hepatotoxicity \\
\hline & Nausea/vomiting & & \\
\hline \multirow[t]{3}{*}{ Renal } & Proteinuria & Haematuria & Nephrotic syndrome \\
\hline & & & Rapidly progressive glomerulonephritis \\
\hline & & & Membranous or proliferative \\
\hline \multirow[t]{2}{*}{ Haematological } & & Thrombocytopenia & Haemolytic anaemia \\
\hline & & Neutropenia & Aplastic anaemia \\
\hline \multirow{2}{*}{$\begin{array}{l}\text { Lung } \\
\text { Muscular }\end{array}$} & & & Bronchiolitis obliterans, alveolitis \\
\hline & & $\begin{array}{l}\text { See autoimmune } \\
\text { phenomena }\end{array}$ & \\
\hline \multirow{6}{*}{$\begin{array}{l}\text { Autoimmune } \\
\text { phenomena }\end{array}$} & Circulating & Myasthenia gravis & Drug induced SLE \\
\hline & & Pemphigus & Goodpasture’s syndrome \\
\hline & & & Polymyositis/dermatomyositis \\
\hline & & & Hypoglycaemia related to anti-insulin \\
\hline & & & antibodies \\
\hline & & & Sjögren’s syndrome \\
\hline
\end{tabular}

Forty to sixty per cent of the patients treated with D-Penicillamine develop adverse events, in $20-30 \%$ this results in treatment discontinuation..$^{8-13}$ D-Pen toxicity pattern in patients with SSc is similar to that observed in RA. ${ }^{910}$

and ankylosing spondylitis (AS). In our case, the a priori chance for the presence of AS was very low. Despite the patient's posture, his age, the lack of inflammatory back pain, and familiar history were not suggestive for spondylarthropathy. Moreover, physical examination revealed no fixed kyphosis but a dropped head and the sacroiliac joints were normal on radiography. The use of HLA B27 testing and sacroiliac joint imaging in such case deserves further comment.

The HLA-B27 test is considered of diagnostic value in patients with a history and physical examination suggestive of AS (high pre-test likelihood) but whose radiological findings do not permit this diagnosis to be made. In this context, testing for HLA B27 allows the presumptive diagnosis to be accepted or rejected with greater certainty. ${ }^{1}$ Conversely, as exemplified in our case, HLA-B27 testing is inappropriate if AS is not suggested by history or physical examination, as a positive result does not permit the diagnosis to be made. ${ }^{1}$ Similar considerations are appropriate concerning the use of computed tomography to detect sacroiliac joint involvement. Though computed tomography is more sensitive than radiography in the recognition of sacroiliitis, it should be reserved for patients with normal or equivocal radiographs if AS is highly suspected. ${ }^{1}$ We therefore consider that HLAB27 typing and computed tomography of the pelvis could have been omitted in our case.

\section{The increased "liver enzymes" and mild proteinuria were attributed to $D$-Pen treatment. Was this appropriate?}

The presence of an increased ASAT, ALAT, and $\mathrm{LDH}$ often suggests concomitant liver disease or hepatotoxicity. Hepatic involvement related to SSc is rare (prevalence less than $10 \%$ ), but should be considered in the diagnosis. ${ }^{2}{ }^{3}$ Primary biliary cirrhosis (PBC) is the most frequent liver disorder related to SSc, especially to the CREST variant. PBC is a progressive cholestatic disorder, associated with the presence of antimitochondrial antibodies
(AMAs in more than $90 \%$ of the cases) and increased serum IgM concentrations. ${ }^{2-4}$ The presence of AMAs is however not diagnostic for PBC because these autoantibodies have been reported in $7 \%-25 \%$ of the patients with SSc only a fraction of whom develop PBC. ${ }^{23}$ Our patient presented no evidence of cholestasis or AMAs.

Proteinuria, nephrotic syndrome and, much less frequently hepatotoxicity can indeed complicate D-Pen treatment (table 1). In our case, the prominent muscular symptoms and the absence of cholestasis or AMAs should have prompted measurement of creatine kinase concentrations to exclude a "myogenic" explanation for these abnormal "liver function tests". Moreover, the increased ESR should have raised the suspicion of concomitant disease as this is not a usual feature of SSc.

\section{What should be the differential diagnosis in this patient?}

Though initially ascribed to sclerosis of the skin, the progressive cervical anteflexion was not fixed and could be corrected to a great extent on recumbence. Severe weakness of neck extensor muscles resulting in a head drop can appear either isolated or be a manifestation of several neuromuscular disorders. ${ }^{5}$ In our case, this symptom was accompanied by proximal weakness, which is the cardinal manifestation of myopathies. The differential diagnosis can be divided into two categories. The first includes myopathies related to either the underlying disease (SSc alone or in overlap with other disorders) or its treatment (in our case myasthenia or polymyositis related to D-pen). The second encompasses myopathies because of potential concurrent disease, such as malignancies, infections, metabolic, endocrine disorders, etc (table 2).

Despite an extensive search, we found no evidence for concomitant disease, including malignancies (see later). Our patient was not immunocompromised and had no history of a previous or ongoing infection. Nevertheless, it should be kept in mind that viral infections are 
Table 2 Conditions associated with myopathies and idiopathic inflammatory myositis (IIM) ${ }^{14}$

\begin{tabular}{|c|c|c|}
\hline & Myopathies & Polymyositis and other IIM \\
\hline Autoimmune diseases & $\begin{array}{l}\text { Rheumatoid arthritis, systemic lupus erythematosus, } \\
\text { Sjögren's syndrome, systemic sclerosis, vasculitis, polymyalgia } \\
\text { rheumatica, sarcoidosis, fibrositis, fasciitis, relapsing } \\
\text { panniculitis, graft versus host disease, etc }\end{array}$ & $\begin{array}{l}\text { Idiopathic inflammatory myositis: PM, DM, IBM } \\
\text { PM in overlap with: systemic sclerosis, mixed connective } \\
\text { tissue disease, systemic lupus erythematosus, Sjögren's } \\
\text { syndrome }\end{array}$ \\
\hline Infectious & $\begin{array}{l}\text { Several viral, bacterial, and some fungal and parasitic } \\
\text { infections can cause acute or chronic myopathy. Some } \\
\text { pathogens and opportunistic infections can cause acute } \\
\text { myositis including pyomyositis and rhabdomyolysis }\end{array}$ & $\begin{array}{l}\text { HIV and HTLV-I and echovirus can induce a PM/DM-like } \\
\text { illness. Unconfirmed reports sugest a relation between } \\
\text { coxackie virus, parvomumps virus, hepatitis C or toxoplasma } \\
\text { infections and IIM }\end{array}$ \\
\hline Toxic & $\begin{array}{l}\text { Alcohol, cocaine, several venoms } \\
\text { Many drugs including amiodarone, cimetidine, } \\
\text { corticosteroids, colchicine, chloroquine, cyclosporine, } \\
\text { emetine, ipecac, propylthiouracil, zidovudine. Several } \\
\text { antibiotics, antineoplastic drugs, diuretics, lipid lowering } \\
\text { agents, } \beta \text { adrenergic blockers and agonists, neuroleptics }\end{array}$ & Thiols: D-penicillamine, tiopronin, pyrithioxine \\
\hline Malignancy & $\begin{array}{l}\text { Carcinomatous myopathy, cachexia, microemboli, carcinoid } \\
\text { myopathy, Lambert-Eaton syndrome }\end{array}$ & Malignancy associated with DM \\
\hline Metabolic & Electrolyte disorders, uraemia, hepatic failure & \\
\hline Endocrine & (Para)thyroid, adrenal, hypophisair pathology & \\
\hline Nutritional & Deficiency of vitamin D or E, malnutrition & \\
\hline Neurological & Myopathy associated with myastenia gravis & \\
\hline Inherited & $\begin{array}{l}\text { Glycogenoses, mytochondrial and lipid storage myopathies, } \\
\text { carnitine deficiency. Familial periodic paralysis } \\
\text { Congenital myopathies: muscular dystrohies and myotonic } \\
\text { disorders }\end{array}$ & \\
\hline Other & $\begin{array}{l}\text { Disuse, ischaemia, physical trauma, hyperpyrexia, amyloid } \\
\text { myopathy, thalassaemia, etc }\end{array}$ & \\
\hline
\end{tabular}

Inflammatory infiltrates may be present in myopathies associated with autoimmune and infectious diseases. Polymyositis (PM), dermatomyositis (DM), inclusion body myositis (IBM), human T cell leukaemia-lymphoma virus type I (HTLV-I).

the most common cause of (sub)acute myopathy in industrialised countries and that HIV, HTLV-I, and echovirus may induce a PM/DMlike disease. ${ }^{67}$ Because of the proteinuria, myeloma and amyloidosis were considered but the absence of monoclonal gammopathy and amyloid deposits made both entities very unlikely. Myasthenia gravis was also considered as it is a recognised complication of D-pen treatment. ${ }^{8-14}$ However, our patient had neither clinical signs (involvement of facial/ocular muscles, worsening of fatigue on repetitive muscular contraction) nor laboratory signs (antibodies against acetylcholine receptors or skeletal muscle) suggestive of this condition.

Were there any other diagnostic clues? Dysphagia and dyspepsia are very common in SSc and usually caused by distal oesophageal hypomotility, reflux or strictures. The skeletal, upper portion of the oesophagus is rarely involved in this disorder. Our patient presented a new "oropharyngeal" dysphagia with choking, nasal voice, contrast aspiration, and cricopharyngeus muscle spasm, which are more frequent in inflammatory myopathies such as polymyositis (PM), dermatomyositis (DM), and inclusion body myositis (IBM).

Our patient fulfilled the diagnostic criteria of PM and had neither rash (DM) nor peripheral muscle weakness, or basophilic vacuoles on the muscle biopsy (IBM). PM has been defined as an inflammatory myopathy with a slow onset of weeks to months and steady progression that occurs mainly in adults. ${ }^{6-15}$ Depending on the criteria set used, this PM could be considered definite $^{15}$ or probable ${ }^{6}$ in view of the scarce inflammatory infiltrates (table $3 \mathrm{~A}$ and $\mathrm{B}$ ).

PM may present separately or, as in our case, associated with other autoimmune diseases. The diagnosis requires the exclusion of other inflammatory myopathies including DM and IBM. ${ }^{6} \mathrm{PM}$ is only rarely induced by exogenous toxic or infectious agents listed in table 2 .
Possible associations between the appearance of PM and previous treatment, the SSc itself, or an underlying malignancy were considered in our patient. These diagnostic categories will be discussed in more detail.

\section{Is PM a frequent complication of drug treatment?}

With the few exceptions shown in table 2, drugs do not cause PM but a toxic, noninflammatory myopathy. D-Pen is a thiol compound derived from the hydrolysis of penicillin. This drug has been used for many years in the treatment of rheumatoid arthritis (RA), SSc, and Wilson's disease. The development of autoantibodies and, less frequently, autoimmune phenomena are well recognised complications of D-Pen treatment (table 1). In patients with RA, the estimated incidence of $\mathrm{PM} / \mathrm{DM}$ induced by D-Pen ranges from $0.2 \%$ to $1.4 \% .^{816-18}$ To date, only eight cases of this complication have been reported in other diseases, including four patients with $\mathrm{Ssc}^{19-22}$ and four with Wilson's disease, ${ }^{23}$ juvenile RA, ${ }^{24}$ psoriatic arthritis and primary biliary cirrhosis $^{25}$ respectively.

The development of PM associated with D-Pen is idiosyncratic and does not depend on the dose or duration of treatment. This complication might be underreported because its clinical, laboratory, and histopathological features are indistinguishable from those seen in idiopathic PM.

\section{Is there a relation between PM and SSc?} Whereas most patients with pure SSc (no overlap) have no muscular complaints, up to $80 \%$ present signs of myopathy, such as muscular weakness or atrophy on examination, and $10 \%$ manifest some clinical, biochemical or histological evidence suggesting an inflammatory myopathy. ${ }^{26} 27$

Clements et al proposed two possible patterns of muscular involvement in SSc. The 
most common is a non-progressive, corticosteroid-resistant myopathy characterised by mild proximal weakness and normal or slightly increased CK. The EMG may present myopathic changes but lacks the insertional irritability and fibrillations seen in PM. Biopsy may show some atrophy but no evident inflammatory infiltrates or fibre degeneration. The second pattern, with clinical, electromyographical, and histological features identical to classic PM, is readily responsive to corticosteroids and most likely to occur in the setting of an overlap syndrome. ${ }^{26}$ The proportion of patients with SSc presenting an overlap with $\mathrm{PM}$ is not exactly known. Conversely, up to $4 \%-7 \%$ of patients with PM have overlapping features with Ssc. ${ }^{15}$ 28-30 In PM-SSc overlap syndromes, features of both diseases are likely to appear early in the disease course. The presence of certain autoantibodies (see later) may help to identify this patient subset.

\section{Are there associations between PM or SSc and malignancy?}

Because of the considerable weight loss and cachexia at referral, our patient underwent an examination, including chest radiography, upper gastrointestinal series and abdominal echography to rule out malignancy.

In patients with SSc, the risk of lung cancer is increased and this seems independent from smoking and related to the presence of lung fibrosis. ${ }^{31}$ Concerning the inflammatory myopathies, it is generally agreed that the incidence of malignancies is increased in patients with DM. The possible association of PM and cancer remains controversial but its rate is lower than that for DM and may not differ from the general population. ${ }^{62}$ Interest-
KEY MESSAGES

- The cardinal manifestation of most myopathies is proximal weakness. This symptom may be mild and confused with fatigue, but also so severe as to result in head drop and dysphagia.

- Abnormal "liver function tests" may be manifestations of myopathy.

- With a few exceptions, such as D-Pen, drugs do not cause PM but a toxic non-inflammatory myopathy.

- Approximately $40 \%-60 \%$ of patients develop adverse events while receiving D-Pen treatment. Although infrequently, the drug induces autoimmune phenomena that fully mimic idiopathic autoimmune diseases.

ingly, patients with cancer associated with PM/DM rarely present features of overlap with other collagen diseases or have myositis specific antibodies. $^{32}$

\section{What was the working diagnosis in this patient?}

Dermatomyositis and inclusion body myositis were excluded and we found no evidence of concurrent malignancy or infection. An overlap PM-SSc seemed unlikely because PM appeared three years after the initial clinical manifestations of SSc without any previous symptoms or autoantibodies characteristic for an overlap syndrome. The working diagnosis consisted of D-Pen induced PM, which was sustained by the concurrent proteinuria, a relatively common complication of the drug (table $1)$. Unexplained low level proteinuria is rare $(<2 \%)$ in patients with SSc. ${ }^{33}$

Table 3

\begin{tabular}{|c|c|c|c|c|c|}
\hline Criteria & \multicolumn{5}{|l|}{ Description } \\
\hline Muscle strength & \multicolumn{5}{|c|}{$\begin{array}{l}\text { Symmetrical weakness of limb girdle muscles and anterior neck flexors, progressing over weeks to months, with/without dysphagia or } \\
\text { respiratory muscle involvement }\end{array}$} \\
\hline Muscle enzymes & \multirow{2}{*}{\multicolumn{5}{|c|}{$\begin{array}{l}\text { Increased, particularly CK and often aldolase, aspartate aminotransferase, alanine aminotransferase, and lactate dehydrogenase } \\
\text { Triad of short, small, polyphasic motor units, fibrillations, positive sharp waves and insertional irritability, and bizarre, high frequency } \\
\text { repetitive discharges }\end{array}$}} \\
\hline Electromyography & & & & & \\
\hline Muscle biopsy & \multirow{2}{*}{\multicolumn{5}{|c|}{$\begin{array}{l}\text { Evidence of necrosis of myofibres, phagocytosis, regeneration with basophils, large vesicularsarcolemmal nuclei, and prominent nucleoli, } \\
\text { atrophy in a perifascicular distribution, variation in fibre size and inflammatory exudates, often perivascular } \\
\text { Any of the characteristic dermatological features of the rash of dermatomyositis }\end{array}$}} \\
\hline Skin & & & & & \\
\hline Diagnosis & \multicolumn{2}{|l|}{ Definite } & \multicolumn{2}{|l|}{ Probable } & Possible \\
\hline $\begin{array}{l}\text { Polymyositis: no rash } \\
\text { and }\end{array}$ & \multicolumn{2}{|l|}{4 criteria } & 3 criteria & & 2 criteria \\
\hline $\begin{array}{l}\text { Dermatomyositis: } \\
\text { rash and }\end{array}$ & \multicolumn{2}{|l|}{3 criteria } & 2 criteria & & 1 criterium \\
\hline \multicolumn{6}{|c|}{ B Classification and diagnostic criteria for inflammatory myopathy according to Dalakas ${ }^{6}$} \\
\hline & Definite $P M$ & Probable $P M^{\star}$ & Definite DM & Mild/Early DM & Definite IBM \\
\hline Muscle strength & $\begin{array}{l}\text { Myopathic } \\
\text { weakness } \dagger\end{array}$ & Myopathic weakness & $\begin{array}{l}\text { Myopathic } \\
\text { weakness }\end{array}$ & Seemingly normalł & $\begin{array}{l}\text { Myopathic weakness, distal muscles } \\
\text { early involved }\end{array}$ \\
\hline Muscle enzymes & Increased & Increased & $\begin{array}{l}\text { Increased or } \\
\text { normal }\end{array}$ & Increased or normal & Increased or normal \\
\hline EMG & Myopathic & Myopathic & Myopathic & Myopathic or non-specific & Myopathic with mixed potentials \\
\hline Muscle biopsy & Diagnostic for PM & $\begin{array}{l}\text { Non-specific myopathy, no } \\
\text { signs of inflammation }\end{array}$ & $\begin{array}{l}\text { Diagnostic for } \\
\text { DM }\end{array}$ & $\begin{array}{l}\text { Diagnostic for DM or } \\
\text { non-specific }\end{array}$ & Diagnostic for IBM \\
\hline Rash or calcinosis & Absent & Absent & Present & Present & Absent \\
\hline
\end{tabular}

${ }^{\star}$ An adequate trial of prednisone or other immunosuppressive drug warranted in probable cases. If, in retrospect, the disease does not respond to treatment, consider another muscle biopsy to exclude other diseases or possible evolution to inclusion body myositis. †Myopathic muscle weakness, affecting proximal muscles more than distal ones and sparing eye and facial muscles, is characterised by a subacute onset and rapid progression in patients who have no family history of neuromuscular disease, no endocrinopathy, no exposure to myotoxic drugs or toxins, and no biochemical muscle disease (excluded by biopsy). $\ddagger$ Although strength is seemingly normal, patients often have new onset of easy fatigue, myalgia, and reduced endurance. Careful examination may show mild muscle weakness. Abbreviations as in table 2 
Table 4 Autoantibodies in PM/DM, overlap syndromes, and SSc. Approximate frequency per group, clinical and genetic associations

\begin{tabular}{|c|c|c|c|c|c|c|}
\hline Antibody & $P M / D M$ & Overlap & $S S c$ & Clinical association & HLA association $\neq$ & Reference \\
\hline ANA & $2 \%$ & $10-70 \%$ & $60-98 \%$ & & & 1516282952 \\
\hline $\mathrm{RF}$ & $5 \%$ & $10-40 \%$ & $25-30 \%$ & & & \\
\hline \multicolumn{7}{|l|}{ Myositis specific autoantibodies } \\
\hline Anticytoplasmic tRNA synthetases & & & & & & $4734-364052$ \\
\hline Jo-1 & $30 / 5 \%$ & $5-15 \%$ & $<5 \%$ & Anti-synthetase syndrome ${ }^{\star}$ & DR3, DR52 & \\
\hline PL-7, PL-12, OJ, EJ & $<5 \%$ & rare & rare & Anti-synthetase syndrome & DR52 & \\
\hline Anticytoplasmic SRP particle & $<5 \%$ & unknown & unknown & Severe PM, cardiac involvement & DR5, DR52 & \\
\hline Anti-Mi-2 (nuclear helicase) & $-10-15 \%$ & unknown & unknown & Classic DM & DR7, DR53 & \\
\hline Anti-KJ & $<1 \%$ & unknown & unknown & PM with lung fibrosis & not reported & \\
\hline Anti-FER & $<1 \%$ & unknown & unknown & Nodular myositis & not reported & \\
\hline Anti-MAS & $<1 \%$ & unknown & unknown & Alcoholic rhabdomyolisis & not reported & \\
\hline “Overlap" autoantibodies & & & & & & $4363740-435253$ \\
\hline Anti-PM-Scl (nuclear/nucleolar) & $10 /<5 \%$ & $10-25 \%$ & $2-4 \%$ & PM-SSc overlap (white population) & B8/DR3 & \\
\hline Anti-Ku (nuclear) & $0-10 \%$ & $20-30 \%$ & $15-40 \%$ & PM-SSc overlap (Japanese) & DR9, DQw1 & \\
\hline Anti-U1 RNP & $10 / 5 \%$ & $30-40 \%$ & $10 \%$ & MCTD, pulmonary hypertension & DR4, DR53, DQB1 & \\
\hline Anti-U2 RNP & $<5 \%$ & $<5 \%$ & unknown & PM-SSc overlap & not reported & \\
\hline Anti DNA-PKcs & $<5 \%$ & $<5 \%$ & unknown & PM, PM-SSc overlap & not reported & \\
\hline "Scleroderma" autoantibodies & & & & & & $452-54$ \\
\hline Anti-Scl-70/topo I (nuclear) & rare & $20 \%$ & $20-70 \%$ & Diffuse SSc, pulmonary fibrosis & DR5, DQB1 & \\
\hline Anti-centromere & rare & $16 \%$ & $20-40 \%$ & $\begin{array}{l}\text { Limited SSc, pulmonary } \\
\text { hypertension }\end{array}$ & DR1, DR4, DR5, DQB1 & \\
\hline Anti-nucleolar, that is & unknown & unknown & $8-20 \%$ & Depending on the specificity & not reported & \\
\hline anti-RNA polymerase III & unknown & unknown & $20-40 \%$ & Diffuse SSc, severe skin and renal & not reported & \\
\hline anti-Th/To RNP & unknown & unknown & $<10 \%$ & Limited SSc, puffy hands & not reported & \\
\hline anti-U3 RNP (fibrillarin) & unknown & unknown & $<10 \%$ & Diffuse SSc, pulmonary hypertension & not reported & \\
\hline
\end{tabular}

^Anti-synthetase syndrome $=$ interstitial lung disease, fever, arthritis, Raynaud’s phenomenon, mechanic hands. $\dagger$ Less often myositis. $\ddagger$ In white populations. The so called mixed connective tissue disease (MCTD). Other abbreviations as in table 2.

The causal role of D-Pen would have been confirmed either by resolution of the symptoms solely on drug withdrawal or in the case of relapse on rechallenge. The severity of the symptoms compelled us to treat with corticosteroids and methotrexate and discouraged rechallenge with D-Pen.

\section{Do serological diagnosis or HLA typing} help to discern between pure PM, overlap syndromes, and PM/DM associated with D-Pen treatment or malignancies?

DIAGNOSTIC USE OF AUTOANTIBODIES

Unlike most non-inflammatory myopathies, autoantibodies to nuclear or cytoplasmic antigens, or both, are commonly found in inflammatory myopathies and SSc. Some of these autoantibodies are considered more specific for idiopathic PM/DM, PM-SSc-overlap and pure SSc and are associated with certain clinical features or HLA alleles, or both (table 4).

Among the myositis specific antibodies, antiJo-1 (anti-histidyl-tRNA synthetase) is considered specific for idiopathic PM and observed rarely, if ever in other myopathies or in connective tissue diseases. ${ }^{34}$ Anti-Jo-1 and other anti aminoacyl-tRNA synthetases are associated with the "antisynthetase syndrome" consisting of interstitial lung disease, arthritis, and Raynaud's phenomenon. ${ }^{34-36}$

In patients with SSc, an overt PM is more frequently observed in those with anti-U1 RNP (U1 small nucleoprotein particle), ${ }^{37-39}$ anti-PM$\mathrm{Scl}^{40}$ and anti-Ku antibodies. ${ }^{41-43}$ Anti-U1 RNP antibodies are commonly seen in patients with unclassified connective tissue diseases, which eventually develop systemic lupus erythematosus, SSc, PM/DM, RA or a combination of these disorders. ${ }^{37-39}$ Anti-PM-Scl is an antinucleolar antibody found in myositisscleroderma overlap as well as in pure forms of PM and SSc. Overall $40 \%-90 \%$ of patients with anti-PM-Scl antibodies have PM-SSc overlap and 3\%-5\% have SSc without myositis. ${ }^{40}$
Rheumatoid factors, ANA, anti-DNA, and more disease specific autoantibodies such as anti-dsDNA, anti-skeletal muscle, and antiacetyl choline receptor autoantibodies have been detected in PM complicating D-Pen therapy but may also appear without clinical evidence of autoimmune disease. There have only been two reports of D-Pen induced PM presenting anti-Jo- $1 .{ }^{44}{ }^{45} \mathrm{With}$ this exception, neither myositis nor overlap syndrome related autoantibodies have been reported in PM induced by D-Pen. It seems therefore that, although the detection of specific autoantibodies may point to an underlying overlap syndrome, it does not exclude a drug related event. Myositis specific antibodies are rarely observed in PM/DM associated with malignancies. ${ }^{32}$

\section{DIAGNOSTIC USE OF HLA TYPING}

Idiopathic PM in adults is associated with HLA B8/DR3 in white populations, B7/DRw6 in black populations, and DQA $1^{\star} 0501$ and or ${ }^{\star} 0401$ in both races. ${ }^{7640}$ Closer associations are observed between certain HLA alleles and myositis specific antibodies (table 4 ).

Dissimilar to idiopathic PM, HLA B8/DR3 does not confer susceptibility to PM induced by $\mathrm{D}$-Pen. Instead, an increased frequency of HLA B18, Bw35, and DR4 in white populations, ${ }^{36} 46$ and DR2 DQw1 in Asian Indians ${ }^{18}$ has been reported in patients with this complication. In a similar way, the association of HLA B8/DR3 and idiopathic myasthenia gravis is not observed in myasthenia related to D-Pen. In this complication an increased prevalence of HLA Bw35 and DR1 has been observed in patients with RA. ${ }^{47}$

It should be mentioned that the associations of HLA with D-Pen induced PM and myasthenia have been reported mostly in patients with RA and cannot be directly extrapolated to SSc.

Our case was HLA DR3 positive and this antigen is associated with an increased risk for proteinuria related to D-Pen (and gold) 
treatment in RA and Ssc. ${ }^{1048}$ The relative risk conferred by this association is too low to be accounted for in the clinical care. ${ }^{48}$

Taken together, certain "myositis related" serum autoantibodies show specific clinical correlations and may help to distinguish between idiopathic PM/DM overlap syndromes and non-inflammatory myopathies. Conversely, despite the association between certain HLA antigens with autoantibodies and/or increased risk for D-Pen toxicity, HLA typing is of little use in establishing the diagnosis or for selecting the treatment for an individual patient.

D-Pen treatment may induce autoantibody production either with or without symptoms. Therefore we consider that discontinuation of treatment is warranted only if autoantibodies occur with concurrent features of autoimmune disease. The clinical evolution and changes in serological parameters thereafter may confirm the diagnosis a posteriori, especially if corticosteroids are not needed. In the case presented, neither serological investigations nor HLA typing provided a clue as to the diagnosis.

\section{The biopsy findings in our case showed severe myopathic changes but not a pronounced inflammatory infiltrate. What can be the explanation?}

Besides degeneration and regeneration of muscle fibres, a characteristic histopathological finding of myositis is the presence of inflammatory infiltrates. The localisation and cellular composition of these infiltrates are distinct in PM and DM. In the latter, inflammatory infiltrates are predominantly perivascular and between fascicles and consist mainly of CD4+ $\mathrm{T}$ and $\mathrm{B}$ cells. In PM however, the infiltrates are found within the fascicles and consist of $\mathrm{CD} 8+\mathrm{T}$ cells and macrophages that surround and invade non-necrotic myocites expressing HLA class I antigen..$^{9-50}$ According to Dalakas (table 3B), inflammation is required to establish the diagnosis of definite PM but not DM or inclusion body myositis. ${ }^{6}$ However, up to $15 \%-20 \%$ of muscle biopsy specimens in typical cases of myositis are not diagnostic. ${ }^{70}$ This may be because of sampling error, because histological changes in PM are patchy and may even be focal. Moreover, less inflammation can be expected if a biopsy specimen is obtained during corticosteroid treatment or in the chronic phase of the disease. This justifies the rationale of diagnostic criteria based on not only histological but also clinical, laboratory, and EMG features. ${ }^{715}$

In our case, the muscle biopsy specimen was obtained from the quadriceps, which was clinically weak and presented contralateral myopathic changes on EMG. This muscle is commonly selected for biopsy because it is involved in most myopathies, is easily accessible, and is devoid of large neurovascular structures. A biopsy specimen from the more severely affected paraspinal neck muscles might have yielded more signs of inflammation. This biopsy site is certainly indicated if isolated focal myositis of the erector spinae is suspected. ${ }^{51}$
Was the treatment for this case justified? Corticosteroids, either alone or combined with corticosteroid sparing agents, remain the treatment of choice for idiopathic PM/DM. In D-Pen induced myositis, recovery after discontinuating treatment has been reported, though corticosteroids are required in most cases. ${ }^{182346}$ In view of the disabling complaints of our patient we considered corticosteroid treatment justified. MTX was added, not only as a corticosteroid sparing agent with confirmed effectivity on $\mathrm{PM}^{651}$ but also as maintenance treatment for SSc.

\section{Conclusion}

We describe a patient with SSc who developed PM and proteinuria during D-Pen treatment. This drug is one of the few agents able to induce an inflammatory myositis that is fully identical to the idiopathic form. The case illustrates the pitfalls in the diagnosis of disorders with protean and partly overlapping manifestations such as PM and SSc.

We wish to thank Henk J ter Laak who carried out the histological study.

1 Khan MA. Ankylosing spondylitis: clinical features. In: Klippel JH, Dieppe PA, eds. Rheumatology. London: Mosby-Year Book Europe Limited, 1994:3.25.1-10.

2 Shorrock CJ, Rees WDW. Gastrointestinal manifestations of Shorrock CJ, Rees WDW. Gastrointestinal manifestations of
systemic sclerosis. In: Jayson MIV, Black CM, eds. Systemic systemic sclerosis. In: Jayson MIV, Black CM, eds. Systemic
sclerosis: scleroderma. Chichester: John Wiley, 1988:167-80.

3 sclerosis: scleroderma. Chichester: John Wiley, 1988:167-80. hepatic manifestations. In: Clements PJ, Furst DE, eds. Systemic sclerosis. Baltimore: Wilkins and Wilkins, 1996: 453-81.

4 Douvas A. Pathogenesis: serologic correlates. In: Clements PJ, Furst DE, eds. Systemic sclerosis. Baltimore: Wilkins and Wilkins, 1996:175-202.

5 Katz JS, Wolfe GI, Burns DK, Bryan WW, Fleckenstein JL, Barohn RJ. Isolated neck extensor myopathy: a common cause of dropped head syndrome. Neurology 1996;46: $917-21$

6 Dalakas $M$. Current treatment of the inflammatory myopathies. Curr Opin Rheumatol 1994;6:595-601.

7 Medsger TA, Oddis CV. Inflammatory muscle disease. In: Klippel JH, Dieppe PA, eds. Rheumatology. London: Klippel JH, Dieppe PA, eds. Rheumatology. Lond
Mosby-Year Book Europe Limited, 1994:6.12.1-14.

8 Cooperative systematic studies of rheumatic disease group. Toxicity of longterm low dose D-penicillamine therapy in rheumatoid arthritis. J Rheumatol 1987;14:67-73.

9 Steen VD, Medsger TA, Rodnan GP. D-penicillamine Steen VD, Medsger TA, Rodnan GP. D-penicillamine
therapy in progressive systemic sclerosis (scleroderma). A retrospective analysis. Ann Intern Med 1982;97:652-8.

10 Steen VD, Blair S, Medsger TA. The toxicity of D-penicillamine in systemic sclerosis. Ann Intern Med 1986;104:699-705.

1 Lipsky PE. Gold, penicillamine and antimalarials. In: Gallin JI, Goldstein IM, Synderman R, eds. Inflammation: basic principles and clinical correlates. New York: Raven Press, 1988:897-909.

12 Hart LE, Tugwell P. The use of disease modifying antiheumatic drugs in the management of rheumatoid arthritis. Postgrad Med J 1989;65:905-12.

13 Kavanaugh AF, Lipsky PE. Gold, penicillamine, antimalarials and sulfasalazine. In: Gallin JI, Goldstein IM, Synderman R, eds. Inflammation: basic principles and clinical man R, eds. Inflammation: basic principles and
correlates. New York: Raven Press, 1992:1083-101.

14 Le Quintrec JS, Le Quintrec JL. Drug induced myopathies. Le Quintrec JS, Le Quintrec JL. Drug ind
Baillieres Clin Rheumatol 1991;5:21-38.

15 Bohan A, Peter JB. Polymyositis and dermatomyositis. N Bohan A, Peter JB. Polymyositis
Engl J Med 1975;292:344-7.

16 Dawkins RL, Zilko PJ, Carrano J, Garlepp MJ, McDonald BL. Immunobiology of D-penicillamine. J Rheumatol Suppl 1981;8:56-61

17 Takahashi K, Ogita T, Okudaira H, Yoshinoya S, Yoshizawa $\mathrm{H}$, Miyamoto T. D-penicillamine induced polymyositis in patients with rheumatoid arthritis. Arthritis Rheum 1986; 29:560-4.

18 Taneja V, Mehra N, Nath Singh Y, Kumar A, Malaviya A, Raj Singh R. HLA-D region genes and susceptibility to D-penicillamine-induced myositis. Arthritis Rheum 1990;
33:1445-7.

19 Nishikay M, Funatsu Y, Homma M. Monoclonal gammopathy penicillamine-induced polymyositis and systemic sclerosis. Arch Dermatol 1974;110:253-5.

20 Matsumura T, Kabashima T, Kono I, Yamane K, Sakurai T, Yamaguchi I, et al. Progressive systemic sclerosis with pancytopenia, polymyositis and complete heart block developing after D-penicillamine therapy: a case report. Nihon Naika Gakkai Zasshi 1985;74:92-7. 
21 Santos JC, Velasco JA. Polymyositis due to D-penicillamine in a patient with systemic sclerosis. Clin Exp Dermatol in a patient

22 Leden I, Libelius R. Penicillamine-induced myositis. Scand J Rheumatol 1985;14:12-15.

23 Schraeder DL, Peters HA, Dahl DS. Polymyositis and penicillamine. Arch Neurol 1972;27:456-7.

24 Swartz MO, Silver RM. D-penicillamine induced polymyositis in juvenile chronic arthritis: report of a case. J Rheumatol 1984;11:251-2.

25 Aydintung AO, Cervera R, D’Cruz D, Ramirez G, Asherson RA, Khamashta MA, et al. Polymyositis complicating D-penicillamine treatment. Postgrad Med 1991;67:101820.

26 Clements PJ, Furst DE, Carnion DS, Bohan A, Harris R, Levy J, et al. Muscle disease in progressive sclerosis. Diagnostic and therapeutic consideration. Arthritis Rheum 1978;21:62-71.

27 Medsger TA Jr, Rodnan GP, Moossy J, Vester JW. Skeletal muscle involvement in progressive systemic sclerosis (sclemuscle involvement in progressive systemic scle

28 Hochberg MC, Feldman D, Stevens MB. Adult onset polymyositis/dermato-myositis: an analysis of clinical and laboratory features and survival of the literature. Semin Arthritis Rheum 1986;15:168-78.

29 Koh ET, Seow A, Ong B, Ratnagopal P, Tjia H, Chng HH Adult onset poly-myositis/dermatomyositis: clinical and laboratory features and treatment response in 75 patients. Ann Rheum Dis 1993;52:857-61.

30 DeVere R, Bradley WG. Polymyositis: its presentation morbidity and mortality. Brain 1975;98:637-66.

31 Peters Golden M, Wise RA, Hochberg M, Stevens MB, Wigley FM. Incidence of lung cancer in systemic sclerosis. J Rheumatol 1985;12:1136-9.

32 Callen JP. Myositis and malignancy. Curr Opin Rheumathol 1994;6:590-4.

33 Steen VD, Syed A, Johnson JP, Conte CL, Medsger TA. Renal disease in systemic sclerosis. Arthritis Rheum 1993;36 (suppl):S131.

34 Targoff IN Autonibodie North Am 1992;18:455-82.

35 Targoff IN, Arnett FC, Reichlin M. Antibody to threonyltransfer RNA ennthe Reichlin M. Antibody to throngltransfer RNA synthetase in myositis sera. Arthritis R $1988 ; 31: 515-24$

36 Garlepp MJ. Genetics of the idiopathic inflammatory myopathies. Curr Opin Rheumatol 1996;8:514-20.

37 Sharp GC, Irvin WS, May CM, Holmn HR, McDuffie FC, Hess EV, et al. Association of antibodies to ribonucleoprotein and Sm antigens with mixed connective tissue disease, systemic lupus erythematosus and other rheumatic diseases. N Engl J Med 1976;295:1149-54.

38 Black C, Isenberg DA. Mixed connective tissue disease goodbye to all that. Br J Rheumatol 1992;31:695-700.

39 Van den Hoogen FH, Boerbooms AM, Spronk P, Bootsma $\mathrm{H}$, de Rooij DJ, Kallenberg C, et al. Mixed connective tissue disease - a farewell? Br J Rheumatol 1993;32:348-9.
40 Oddis CV, Rudert WA, Trucco M, Duquesnoy RJ, Medsger TA, Jr. Serum antibody to the nuclear antigen PM-Scl. Clinical and immunogenetic associations. Arthritis Rheum 1992;35:1211-17.

41 Mimori T. Structures targeted by the immune system in myositis. Curr Opin Rheumatol 1996;8:521-7.

42 Reeves WH, Satoh M, Langdon JJ. Clinical significance of autoantibodies to $\mathrm{Ku}$ and related antigens. In: Van Venrooij WJ, Maini RN, eds. Manual of biological markers of disease. Autoantibody manual. Dordrecht: Kluwer Academic, 1996: C2.3:1-11

43 Yaneva M, Arnett FC. Antibodies against Ku protein in sera from patients with autoimmune diseases. Clin Exp Immunol 1989;76:366-72.

44 Jenkins EA, Hull RG, Thomas AL. D-penicillamine and polymyositis: the significance of the anti-Jo-1 antibody. Br J Rheumatol 1993;32:1109-10.

45 Oberlin F, Koeger AC, Meyer O, Rosey Th, Camus JP. D-penicillamine et dermatopolymyosite. Valeur de la recherche des anticorps anti-Jo-1. Presse Med 1986;15: 887.

46 Carroll GJ, Will RK, Peter JB, Garlepp MJ, Dawkins RL. Penicillamine induced polymyositis and dermatomyositis. J Rheumatol 1987;14:995-1001.

47 Garlepp MJ, Dawkins RL, Christiansen FT. HLA antigens and acetylcholine receptor antibodies in penicillamine induced myasthenia gravis. BMF 1983;286:3398-40.

48 Wijnands $\mathrm{MJH}$, van Riel PLCM, Gribnau FWJ, van de Putte LBA. Risk factors of second-line antirheumatic drugs in rheumatoid arthirtis: a review of the literature. Semin Arthritis Rheum 1990;19:337-52.

49 Engel AG, Arahata ZK. Mononuclear cells in myopathies: Quantitation of functionally distinct subjects, recognition of antigen-specific cell-mediated cytotoxicity in some diseases and implication for the pathogenesis of the different inflammatory myopathies. Hum Pathol 1986;17:70421.

50 Karpati G, Pouliat Y, Carpenter S. Expression of immunoreactive major histocompatibility complex products in human skeletal muscles. Ann Neurol 1988;23:54-72.

51 Kagen LJ. Polymyosiyis/Dermatomyositis. In McCarty DJ, ed. Arthritis and allied conditions. Philadelphia: Lea-Febiger, 1993:1225-52.

52 Maddison PJ, Stephens C, Briggs D, Welsh KI, Harvey G, Whyte J, et al. Connective tissue disease and autoantibodies in the kindreds of 63 patients with systemic sclerosis. Medicine (Baltimore) 1993;72:103-12.

53 Steen VD. Autoantibodies in systemic sclerosis. Bull Rheum Dis $1996 ; 45: 6-8$.

54 Xie Y, Miao C. Overlap syndrome of progressive systemic sclerosis and polymyositis: report of 40 cases. Chin Med Sci J 1991;6:107-9. 